\title{
O GRANITO SERRA DOS CARAJÁS, PARÁ: II. CARACTERIZAÇÃO DOS FLUIDOS AQUOSOS E ALTERAÇÃO HIDROTERMAL
}

\author{
FRANCISCO JAVIER RIOS *, RAIMUNDO NETUNO VILLAS** \& \\ KAZUO FUZIKAWA***
}

\begin{abstract}
SERRA DOS CARAJÁS GRANITE, PARÁ: II. CHARACTERIZATION OF AQUEOUS FLUIDS AND HYDROTHERMAL ALTERATION. The weak but widespread hydrothermal alteration of the Serra dos Carajás granite at its northern end consists of chloritization of mafic minerals, serialization or argillization of feldspars and epidptization of biotite, besides albitization, carbonation and, to a lesser degree, silicification of the rocks. Calculations of absolute gains and losses showed a net mass transfer from the granite to the aqueous solutions that varied from $0,03 \mathrm{~g} / \mathrm{cm}^{3}$ in the silica-and albite- rich altered rocks to $0,21 \mathrm{~g} / \mathrm{cm}^{3}$ in the kaolinite-rich altered rocks. For a density of $2,63 \mathrm{~g} / \mathrm{cm}^{3}$ for the unaltered granite, this highest value corresponds to no more than $8 \%$ of mass loss. A discrete sulfide mineralization occurs associated to the hydrothermal alteration, but it represents less than $1 \%$ of the host granite volume; as a result, $\mathrm{Cu}$ and Mo reserves are economically unimportant. Several fracture-filling hydrothermal veins and veinlets are present in the area with different mineral assemblages. Three main types have been identified: 1) calcite-sulfide veins; 2) quartz-albite-chlorite-epidotetourmaline-calcite-fluorite-sufide veins; and 3) sulfide veinlets. Microthermometric data on fluid inclusions in quartz, calcite and fluorite crystals indicated a wide temperature range for mineral precipitation $\left(>520\right.$ to $\left.130^{\circ} \mathrm{C}\right)$ with a gap between $520^{\circ} \mathrm{C}$ and about $200^{\circ} \mathrm{C}$ that probably resulted from mixing of fluids. Hot and very saline aqueous solutions exsolved from the granitic magma, whereas colder and more dilute $\mathrm{CO}_{3} "-\mathrm{H}_{2} \mathrm{~S}$-rich solutions, flowing from the host rocks, penetrated the granite and might have mixed with the magmatic solutions or precipitated directly their metallic load in open fractures. Fluid inclusions in calcite crystals from such structures showed, as opposed to the complex veins, an inverse relation between salinity and homogenization temperature which supports the interpretation of an independent non-magmatic source. Phase relations at $200^{\circ} \mathrm{C}$ in the system FeO- $\mathrm{H}_{2} \mathrm{~S}-\mathrm{H}_{2} \mathrm{O}-\mathrm{O}_{2}$ allowed to fix a $\mathrm{f}_{02}$ range of $10^{40}$ to $10^{45} \mathrm{~atm}$, as well as $\mathrm{f}_{\mathrm{H} 2 \mathrm{~S}}>10^{-5} \mathrm{~atm}$ based on the scarcity of Fe-oxides (magnetite and hematite) and the absence of pyrrhotite. Similarly, in the system $\mathrm{CaO}-\mathrm{Al}_{2} \mathrm{O}_{3}-\mathrm{SiO}_{2}-\mathrm{HF}-$ $\mathrm{H}_{2} \mathrm{O}$ at the same temperature, values of $\log \left(\mathrm{a}_{\mathrm{ca}+} / \mathrm{a}^{2} \mathrm{H}^{+}\right.$and $\log \left(\mathrm{a}_{\mathrm{H}+}\right.$. $\left.\mathrm{a}_{\mathrm{F}}-\right)$ were estimated respectively in 8,9 and $-9,6$, constrained by the fluorite saturation surface and absence of both topaz and lawmontite in the Carajás granite hydrothermal system. In the $200-150^{\circ} \mathrm{C}$ range, $f_{\mathrm{c} 02}$ was calculated to vary from 0,2 to $2 \mathrm{~atm}$ according to those same constraints.
\end{abstract}

Keywords: Serra dos Carajás granite, hydrothermal alteration, absolute gains and losses, fluid inclusions.

RESUMO As rochas expostas na pedreira localizada na extremidade norte do granito Serra dos Carajás mostram uma alteração hidrotermal fraca, ainda que ubiquamente presente. Associados à ela ocorrem sulfetos de $\mathrm{Cu}$ e Mo que constituem, contudo, uma mineralização economicamente inexpressiva. As principais evidências de alteração hidrotermal estão na cloritização dos minerais máficos, sericitização ou argilização dos feldspatos e epidotização da biotita, além da albitização, carbonatação e, em menor grau, da silicificação das rochas. A avaliação das perdas e ganhos absolutos revelou uma transferência global de massa do granito para as soluções aquosas, registrando-se os mais altos valores $\left(0,21 \mathrm{~g} / \mathrm{cm}^{3}\right)$ nas rochas silicificadas e albitizadas. Para uma densidade de $2,69 \mathrm{~g} / \mathrm{cm}^{3}$ para o granito não alterado, o maior valor corresponde a uma perda líquida equivalente a cerca de $8 \%$. Dentre os produtos da alteração hidrotermal, destacam-se veios que se formaram pelo preenchimento de fraturas que cortam o corpo granítico em várias direções. Identificaram-se três tipos principais de veios de acordo com a associação mineralógica que eles contêm: 1) calcita-sulfetos; 2) quartzo-albita-clorita-epidoto-turmalina-calcita-fluorita-sulfetos; e 3) sulfetos. Dados microtermométricos em inclusões fluidas em cristais de quartzo, calcita e fluorita acusaram um amplo intervalo termal para a precipitacão desses minerais $\left(>520\right.$ a $\left.130^{\circ} \mathrm{C}\right)$ com um hiato entre $520^{\circ} \mathrm{C}$ e cerca de $200^{\circ} \mathrm{C}$ o qual foi atribuído à mistura de fluidos. Soluções aquosas muito salinas exsolvidas do magma granítico são responsáveis pelas temperaturas mais altas, enquanto aquelas mais diluídas respondem pela faixa de temperaturas mais baixas. Estas últimas, derivadas das rochas encaixantes, bem mais frias e ricas em espécies de carbonates e sulfetos, penetraram no corpo granítico, misturando-se com os fluidos aquosos magmáticos ou precipitando diretamente sua carga metálica em planos de fratura. Inclusões fluidas em cristais de calcita das vênulas resultantes deste processo apresentam, contrariamente aos veios de estrutura complexa, uma relação inversa entre salinidade e temperatura de homogeneização, o que dá suporte à interpretação de essas soluções derivarem de fonte externa ao granito. Utilizando-se 9 subsistema $\mathrm{FeO}-\mathrm{H}_{2} \mathrm{~S}-\mathrm{H}_{2} \mathrm{O}-\mathrm{O}_{2}$, foram fixadas, a $200^{\circ} \mathrm{C}$, valores de fugacidades de $\mathrm{O}_{2}$ no intervalo de $10^{40} \mathrm{a} 10^{45} \mathrm{~atm}$, bem como fugacidades de $\mathrm{H}_{2} \mathrm{~S}$ superiores a $\mathrm{IO}^{5} \mathrm{~atm}$, com base na escassez de óxidos de ferro (magnetita e hematita) e na ausência de pirrotita. Da mesma forma, o subsistema $\mathrm{CaO}-\mathrm{Al}_{2} \mathrm{O}_{3}-\mathrm{SiO}_{2}-\mathrm{HF}-$ $\mathrm{H}_{2} \mathrm{O}$, à mesma temperatura, permitiu estimar valores para $\log \left(\mathrm{a}_{\mathrm{Ca}+} / \mathrm{a}_{\mathrm{H}+}^{2}\right)$ e $\log \left(\mathrm{a}_{\mathrm{H}+} . \mathrm{a}_{\mathrm{F}-\mathrm{F}}\right)$ respectivamente em 8,9 e $-9,6$, que foram deduzidos a partir da superfície de saturação da fluorita dentro do campo de estabilidade da caolinita, mas fora dos campos da laumontita e do topázio, ambos ausentes no sistema hidrotermal do granito Carajás no setor estudado. Para a fugacidade de $\mathrm{CO}_{2}$, foram estimados valores entre 0,2 e 2 atm na faixa de temperatura entre 150 e $200^{\circ} \mathrm{C}$, observadas aquelas mesmas restrições.

Palavras-chaves: Granito Serra dos Carajás, alteração hidrotermal, perdas e ganhos absolutos, inclusões fluidas.

Curso de Pós-graduacão em Geologia e Geoquímica, Centro de Geociências, Universidade Federal de Pará (UFPA), Av. Augusto Corrêa 1, Caixa Postal 1611, CEP 66075-900, Belém, PA, Brasil. Endereço atual: Centro de Desenvolvimento de Tecnologia Nuclear (CDTN), Comissão Nacional de Energia Nuclear (CNEN), Caixa Postal 941, CEP 31000-000, Belo Horizonte. MG, Brasil, Fone (031) 441.5422, R. 2331

Departamento de Geologia, Centro de Geociências, Universidade Federal do Pará (UFPA), Av. Augusto Corrêa 1, Caixa Postal 1611, CEP 66075-900, Belém, PA, Brasil. Fax (091) 211.1609, Fone (091) 211.1414

Centro de Desenvolvimento de Tecnologia Nuclear (CDTN), Comissão Nacional de Energia Nuclear (CNEN), Campus Universitário da UFMG, Caixa Postal 941, CEP 31000-000, Belo Horizonte, MG, Brasil, Fone (031) 441.5422, R. 2331. 
INTRODUÇÃO A segunda parte desta pesquisa trata especificamente do paleossistema hidrotermal que atuou no setor norte do granito Serra dos Carajás após seu alojamento e que levou à alteração e à precipitação de sulfetos, sem, contudo, proporcionar mineralização de valor econômico. Caracteriza, em particular, a natureza dos fluidos que circularam naquele sistema, bem como as transformações químicas e mineralógicas resultantes da interação fluido-rocha. As mudanças químicas são avaliadas através das perdas e ganhos absolutos de massa, enquanto as condições sob as quais a alteração e mineralização ocorreram são descritas em termos das fugacidades de $\mathrm{O}_{2}, \mathrm{CO}_{2}$, e $\mathrm{H}_{2} \mathrm{~S}$, e do produto das atividades de $\mathrm{H}^{*}$ e de P. Busca-se, assim, detalhar o estágio hidrotermal da evolução petrológica do corpo Serra dos Carajás, avançando no conhecimento das intrusões graníticas anorogênicas da Amazônia Oriental, cujos estudos anteriores limitaram-se aos estágios estritamente magmáticos (Almeida 1980; Dall'Agnol 1982; Dall'Agnol et al 1984 e 1994; Gastai 1988; Gonçalvez et al 1988; Teixeira \& Andrade 1992; dentre outros).

$\mathrm{Na}$ área da intrusão Serra dos Carajás, que foi mapeada, afloram principalmente sienogranitos (fácies ABS) e monzogranitos (fácies ABM), os quais são compostos de proporções variadas de quartzo, feldspato potássico $(\mathrm{FK})$, oligoclásio, biotita e hornblenda hastingsítica, tendo allanita, zircão e apatita como fases acessórias primárias mais comuns. Essas rochas são cortadas por diferentes tipos de diques de microgranitos, que foram derivados do mesmo magma que gerou o corpo intrusivo principal. Descrições petrográficas e análises químicas dessas rochas estão apresentados na parte I desta série $(\mathrm{O}$ granito Serra dos Carajás: I. Fácies petrográficas e avaliaçẫo do potencial metalogenético para estanho do setor norte).

A ALTERAĈ̃̃O HIDROTERMAL DAS ROCHAS GRANÍTICAS A alteração hidrotermal do granito Serra dos Carajás no setor norte, embora generalizada, é fraca, a ponto de virtualmente não modificar a textura primária das rochas. Os sinais mais fortes da alteração podem ser observados em halos de $5 \mathrm{~cm}$ a $2 \mathrm{~m}$ de espessura que se desenvolveram ao longo dos veios, sem constituírem, contudo, verdadeiras zonas de alteração. No interior da massa rochosa constatam-se, em geral, porções que também foram transformadas sem obedecer nenhum padrão geométrico definido e nelas podem ser observados mais de um tipo de alteração. Registram-se, localmente, evidências de incipiente greisenização, que é marcada por altas concentraçôes de mica branca.

Principais tipos de alteração As transformações mineralógicas mais comuns nos anfibólio-biotita sienogranitos levaram à sericitização dos feldspatos, à cloritização da biotita e do plagioclásio, à caolinização do felspato potássico (FK), bem como à introdução de carbonates e sulfetos. Silicificação e albitização também podem ser observadas. Não obstante, além da ocorrência irregular, os minerais secundários não chegam a constituir $10 \%$ do volume total da rocha, podendo ser observados em três diferentes modalidades. Em geral, eles estão contidos nos feldspatos e nas fases máficas. Menos freqüentemente, eles são encontrados em várias combinações como cordões descontínuos que seguem contatos intergranulares de fases primárias. Encontram-se, também, preenchendo planos de fraturas como constituintes de veios ou vênulas.

O FK cede lugar, parcialmente, a argilominerais, resultando numa cor avermelhada que, nas paredes contíguas aos veios, acentua a presença dos halos de alteração. Os cristais apresentam um aspecto turvo, próprio da substituição por caolinita e, em menor escala, por esmectita. Registram-se, subordinadamente à argilização, também sericitização, que é marcada pela presença de mica verde de alta birrefringência, cloritização e carbonatação, esta última representada por vênulas de calcita. Localmente, a albitização do FK origina cristais que lembram um tabuleiro de xadrez, no centro dos quais persiste FK micropertítico reliquiar.

O plagioclásio ocorre totalmente substituído por várias combinações de sericita, clorita, fluorita e calcita. Já não é possível observar com nitidez as macias polissintéticas, que foram fortemente mascaradas pela alteração.

No que respeita às fases ferro-magnesianas, os cristais de anfibólio estão, nos halos de alteração, totalmente substituídos por agregados de clorita + titanita + opacos + epidoto + fluorita + calcita, mas podem ser observados menos intensamente transformados em outros sítios. Já as palhetas de biotita sofreram intenso processo de cloritização e nas zonas de greisenização incipiente é comum a muscovitização. Além da clorita, ocorrem, como produtos de alteração da biotita, a titanita, a calcita e minerais do grupo do epidoto (pistacita e piedmontita).

Encontram-se ainda, nas porções alteradas, grãos de sulfetos, particularmente calcopirita e pirita, alem de quartzo e albita, que se precipitaram em microfraturas.

Os domínios greisenizados resultam da transformação dos anfibólio-biotita monzogranitos para rochas com composição média de $53,2 \%$ de quartzo, $37,0 \%$ de mica branca a verde, $6,5 \%$ de feldspato potássico, $0,6 \%$ de zircão metamítico e $2,7 \%$ de outros minerais. Cassiterita, fluorita e topázio não foram detectados na associação mineralógica dessas rochas.

Do ponto de vista químico, são poucas as diferenças entre sieno-granitos alterados e não alterados (Tab. 1). Os teores médios são praticamente equivalentes, embora certas amostras (ABS-22, ABS-26, ABS-32b, ABS-70 e ABS-91b) estejam bem afastadas de alguns desses valores. As maiores variações verificam-se nos teores de $\mathrm{FeO}(2,25 \% / 1,19 \%)$ e $\mathrm{Fe}_{2} \mathrm{O}_{3}(2,76 \% / 0,86 \%)$, ambos bem mais altos nas rochas alteradas. Em termos das razões moleculares $\mathrm{Fe}_{2} \mathrm{O}_{3} / \mathrm{FeO}$ (Fig.1), $75 \%$ das amostras alteradas que foram analisadas acusam valores dentro do intervalo de 0,50 a 0,70 , bem acima da média de 0,32 calculada para as rochas não alteradas. Apenas três amostras alteradas distribuem-se no intervalo de 0,15 a 0,30 . Estes dados indicam que durante os processos de alteração hidrotermal as condições foram relativamente mais oxidantes do que as que prevaleceram na formação das rochas graníticas. As outras diferenças mais importantes referem-se à entrada e fixação de voláteis $\left(\mathrm{H}_{2} \mathrm{O}\right.$, $\mathrm{CO}_{2}$ e $\mathrm{S}_{2}$ ) nas rochas alteradas sob forma de hidroxi-minerais, carbonates e sulfetos.

Qualitativamente, observa-se que as eventuais áreas silicificadas, como era de se esperar, são as que mostram maiores concentrações de silica (amostra ABS32b, p. ex.), enquanto as mais baixas se verificam naquelas que foram sericitizadas ou caolinizadas (ABS08, ABS10, ABS12, ABS22 e ABS32a, p. ex.). Da mesma forma, os maiores teores de potassa encontram-se nas rochas em que houve sericitização do plagioclásio, levando, em decorrência, a teores de soda relativamente baixos (amostras ABS08, BBS10 e ABS12, p. ex.). Valores mais baixos tanto de soda como de potassa são constatados nas rochas cujo grau de caolinização dos feldspatos foi mais intenso (amostras ABS22 e ABS32a, p. ex.). A soda, em contrapartida, foi enriquecida nas rochas em que a albitização se fez presente (amostras ABS32b e ABS26, p. ex.).

Quanto à alumina, praticamente não há variação, se bem que as menores concentrações são observadas nas rochas que foram tanto silicifícadas como albitizadas (amostra ABS32b). Apesar de pouco expressivos, chama a atencão que os maiores teores de $\mathrm{MnO}(0,05 \%)$ vêm de rochas encaixantes de veios nos quais se registra a presença de epidoto manganesífero (piedmontita). Já os teores médios 


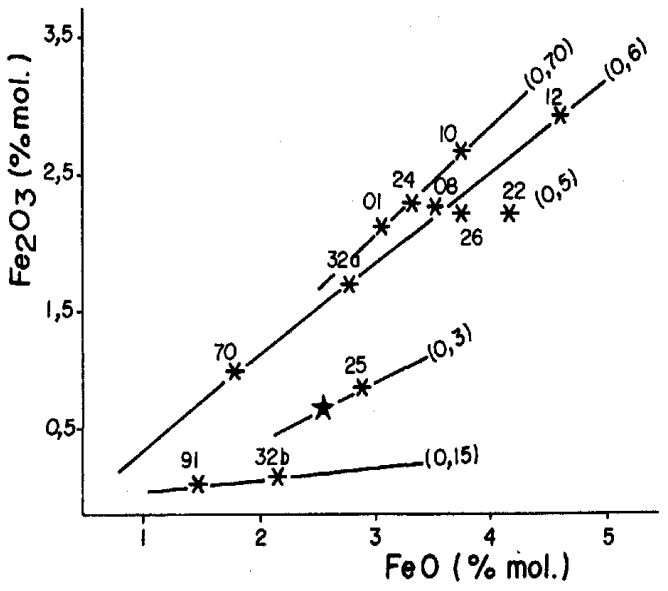

Figura 1 -Diagrama $\mathrm{FeO} \times \mathrm{Fe}_{2} \mathrm{O}_{3}$ (\% molecular) mostrando a distribuição das amostras alteradas da fácies ABS (*). A estrela (*) representa a média de amostras não alteradas da mesma fácies. Os números entre parênteses representam razões moleculares $\mathrm{Fe}_{2} \mathrm{O} / \mathrm{FeO}$

Figure $1-\mathrm{FeO}_{\mathrm{Fe}} \mathrm{O}_{3}$ diagram (molecular \%) showing the distribution of ABS facies altered samples $(*)$. The star $(*)$ represents the average of the ABS facies unaltered samples. Numbers in parentheses represent $\mathrm{Fe}_{2} \mathrm{O}$ $\mathrm{FeO}$ molecular ratios

de $\mathrm{TiO}_{2}$ são cerca de $40 \%$ mais elevados nos sienogranitos alterados que nos não alterados, refletindo a estabilização de titanita secundária a partir da alteração de cristais de anfibólio ou biotita. Por fim, as concentrações de $\mathrm{P}_{2} \mathrm{O}_{5}$ são sistematicamente menores nas rochas alteradas, nas quais a apatita foi em parte destruída.

Com relação aos elementos traços, registram-se, salvo raras exceções, teores extremamente baixos de $\mathrm{Cu}$ nas rochas não alteradas, porém a freqüente presença de microvênulas com calcopirita nas rochas alteradas os eleva até 280 ppm. As concentrações de Rb e Zr são similares em embos os tipos, enquanto as de Sr mostram-se diminuídas nas rochas alteradas, especialmente naquelas em que houve desestabilização da biotita. Chama a atenção que, em três amostras (ABS22, ABS26 e ABS32b), os menores valores de $\mathrm{Rb}$ coincidem com os menores de $\mathrm{Sr}$, ao mesmo tempo em que há em todas diminuição acentuada de $\mathrm{K}_{2} \mathrm{O}$ e, em duas, de $\mathrm{Na}_{2} \mathrm{O}$, refletindo provavelmente a albitização que as rochas sofreram.

Balanço de Massa A correspondência, em termos quantitativos, entre as transformações mineralógicas e químicas observadas no granito Serra dos Carajás foi estudada através do cálculo das perdas e ganhos absolutos de massa em domínios distintamente alterados, com base em dados densimétricos (Javier Rios 1991).

Para as rochas não alteradas, a densidade foi determinada em quatro amostras, as quais forneceram um valor médio de $2,69 \mathrm{~g} / \mathrm{cm}^{3}$. Foram igualmente medidas densidades em quatro amostras (ABS26, ABS70, ABS32 e ABS91b) cada uma representando diferentes tipos de alteração: 1) rocha albitizada rica em clorita; 2 ) rocha rica em carbonates e em argilo-minerais; 3) rocha silicificada e albitizada, e 4) rocha avermelhada com argilização dos feldspatos (Tab.2).

O cálculo da composição química dessas amostras alteradas em termos de massa por unidade de volume revela que, de modo geral, todas elas perderam massa durante os processos hidrotermais (Tab.3). A maior perda foi registrada no tipo $4\left(0,21 \mathrm{~g} / \mathrm{cm}^{3}\right)$, enquanto a menor se deu no tipo $3(0,03$ $\left.\mathrm{g} / \mathrm{cm}^{3}\right)$, implicando que a transferência líquida de massa às soluções aquosas não passou de $8 \%$.

No que respeita aos componentes individuais (Fig.2 e Tab.3), observa-se que eles têm comportamento distinto em função do tipo de alteração considerado. A alumina, por exemplo, é o único componente que sistematicamente foi removido do sistema, acusando perdas entre 0,01 a $0,03 \mathrm{~g} /$ $\mathrm{cm}^{3}$. A silica seguiu o mesmo padrão, com perdas até 16 vezes maiores que a alumina, à exceção do tipo $3 \mathrm{em}$ que ela foi adicionada na proporção de $0,05 \mathrm{~g} / \mathrm{cm}^{3}$. Já o ferro mostra aporte $\left(0,09 \mathrm{~g} / \mathrm{cm}^{3}\right)$, sobretudo no tipo 1 , rico em clorita, sendo lixiviado nos demais $\left(0,01\right.$ a $\left.0,04 \mathrm{~g} / \mathrm{cm}^{3}\right)$, embora na forma trivalente tenha registrado ganhos também no tipo 2.

Tabela 1 - Composição química de rochas hidrotermalmente alteradas do granito Serra dos Carajás, Pará. Elementos maiores em \% de peso e elementos traços em ppm

Table 1 - Chemical composition of the Serra dos Carajás granite hydrothermally altered rocks, Pará. Major elements expressed in weight \% and trace elements in $\mathrm{ppm}$

\begin{tabular}{|c|c|c|c|c|c|c|c|c|c|c|c|c|c|c|}
\hline & ABSO1 & ABS08 & ABS10 & ABSI2 & $\mathrm{ABS22}$ & ABS24 & ABS25 & ABS26 & ABS32a & $A B S 32 b$ & ABS70 & ABS9 & Média & $\begin{array}{l}\text { ABS } \\
\text { (NA) }\end{array}$ \\
\hline $\begin{array}{l}\mathrm{SiO}_{2} \\
\mathrm{TO}_{2} \\
\mathrm{Al}_{2} \mathrm{O}_{3} \\
\mathrm{Fe}_{2} \mathrm{O}_{3} \\
\mathrm{FeO} \mathrm{O} \\
\mathrm{MgO} \\
\mathrm{MnO} \\
\mathrm{CaO} \\
\mathrm{Na}_{2} \mathrm{O} \\
\mathrm{K}_{2} \mathrm{O} \\
\mathrm{P}_{2} \mathrm{O}_{4} \\
\mathrm{CO}_{1} \\
\mathrm{H}_{2} \mathrm{O}\end{array}$ & $\begin{array}{c}74,72 \\
0,31 \\
12,09 \\
3,39 \\
2,24 \\
\text { nd } \\
\text { ad } \\
\text { nd } \\
\text { nd } \\
6,64 \\
0,01 \\
\text { nd } \\
1,09\end{array}$ & $\begin{array}{c}72,84 \\
0,31 \\
12,46 \\
3,68 \\
2,54 \\
\text { nd } \\
\text { nd } \\
\text { nd } \\
2,23 \\
6,16 \\
0,01 \\
\text { nd } \\
0,39\end{array}$ & $\begin{array}{c}70,88 \\
0,34 \\
11,93 \\
4,24 \\
2,68 \\
\text { nd } \\
\text { nd } \\
1,60 \\
2,32 \\
6,08 \\
0,01 \\
\text { nd } \\
0,57\end{array}$ & $\begin{array}{c}70,03 \\
0,43 \\
11,78 \\
4,52 \\
3,33 \\
\text { nd } \\
\text { nd } \\
1,33 \\
2,48 \\
6,31 \\
0,01 \\
\text { nd } \\
0,26\end{array}$ & $\begin{array}{c}72,42 \\
0,37 \\
\mathrm{t1}, 74 \\
3,42 \\
3,00 \\
\text { nd } \\
\text { nd } \\
1,40 \\
1,18 \\
4,83 \\
0,01 \\
\text { nd } \\
1,77\end{array}$ & $\begin{array}{c}72,30 \\
0,44 \\
11,94 \\
3,67 \\
2,41 \\
\text { nd } \\
\text { nd } \\
1,17 \\
2,46 \\
5,48 \\
0,01 \\
\text { nd } \\
0,91\end{array}$ & $\begin{array}{r}73,30 \\
0,14 \\
12,20 \\
1,50 \\
2,10 \\
0,19 \\
0,03 \\
1,40 \\
2,60 \\
5,20 \\
0,01 \\
\text { nd } \\
0,67\end{array}$ & $\begin{array}{c}75,45 \\
0,29 \\
11,95 \\
3,45 \\
2,70 \\
\text { nd } \\
\text { nd } \\
0,26 \\
3,29 \\
2,63 \\
0,01 \\
\text { nd } \\
0,83\end{array}$ & $\begin{array}{r}73,80 \\
0.28 \\
12,38 \\
2,67 \\
2,04 \\
\text { nd } \\
\text { nd } \\
1,33 \\
1,86 \\
4,72 \\
0,01 \\
\text { ind } \\
1,00\end{array}$ & $\begin{array}{r}77,10 \\
0,24 \\
11,10 \\
0,52 \\
1,60 \\
0,10 \\
0,04 \\
1,40 \\
3,10 \\
2,60 \\
0,05 \\
1,10 \\
0,80\end{array}$ & $\begin{array}{r}71,50 \\
0,23 \\
12,40 \\
1,70 \\
1,30 \\
0,45 \\
0,05 \\
1,80 \\
2,20 \\
6,10 \\
0,05 \\
1,20 \\
1,10\end{array}$ & $\begin{array}{r}76,10 \\
0,10 \\
12,30 \\
0,38 \\
1,10 \\
0,10 \\
0,01 \\
0,29 \\
1,90 \\
6,50 \\
0,05 \\
0,45 \\
0,50\end{array}$ & $\begin{array}{c}73,37 \\
0,29 \\
12,02 \\
2,76 \\
2,25 \\
0,21 \\
0,03 \\
1,20 \\
2,33 \\
5,27 \\
0,01 \\
0,92 \\
0,92\end{array}$ & $\begin{array}{r}75,10 \\
0.21 \\
12,37 \\
0,86 \\
1,19 \\
0,15 \\
0,02 \\
1,04 \\
2,58 \\
5,38 \\
0,04 \\
0,43 \\
0,71 \\
\end{array}$ \\
\hline Total & 100,49 & 100,62 & 100,65 & 100,48 & 100.14 & 100.79 & 99.34 & 100.84 & 100,09 & 99.75 & 100,08 & 99.78 & 99.25 & 100,08 \\
\hline $\begin{array}{l}\mathrm{Ba} \\
\mathrm{Sr} \\
\mathrm{Rb} \\
\mathrm{Cu} \\
\mathrm{Zr}\end{array}$ & $\begin{array}{c}\text { nd } \\
\mathbf{1 2 1} \\
\mathbf{1 7 5} \\
\text { nd } \\
\mathbf{3 0 9}\end{array}$ & $\begin{array}{l}\text { nd } \\
140 \\
159 \\
\text { nd } \\
377\end{array}$ & $\begin{array}{c}\text { nd } \\
142 \\
145 \\
\text { nd } \\
337\end{array}$ & $\begin{array}{c}\text { nd } \\
137 \\
158 \\
\text { nd } \\
312\end{array}$ & $\begin{array}{c}\text { nd } \\
29 \\
115 \\
\text { nd } \\
268\end{array}$ & $\begin{array}{l}\text { nd } \\
127 \\
157 \\
279 \\
303\end{array}$ & $\begin{array}{c}\text { nd } \\
132 \\
136 \\
32 \\
397\end{array}$ & $\begin{array}{c}\text { nd } \\
13 \\
83 \\
83 \\
336\end{array}$ & $\begin{array}{l}\text { nd } \\
124 \\
135 \\
\text { nd } \\
334\end{array}$ & $\begin{array}{c}537 \\
43 \\
110 \\
12 \\
440\end{array}$ & $\begin{array}{c}1701 \\
74 \\
160 \\
54 \\
330\end{array}$ & $\begin{array}{l}2418 \\
\text { nd } \\
\text { nd } \\
94 \\
\text { nd }\end{array}$ & $\begin{array}{c}1552 \\
98 \\
139 \\
87 \\
340\end{array}$ & $\begin{array}{l}1822 \\
112 \\
160 \\
\text { id } \\
56\end{array}$ \\
\hline
\end{tabular}


Tabela 2 - Densidades $\left(\mathrm{g} / \mathrm{cm}^{3}\right)$ de rochas não alteradas $e$ equivalentes alteradas da fades ABS do granito Serra dos Carajás, Pará

Table 2 - Densities $\left(\mathrm{g} / \mathrm{cm}^{3}\right)$ of the unaltered and altered ABS facies rocks of the Serra dos Carajás granite, Pará

\begin{tabular}{|c|c|c|c|c|c|}
\hline \multicolumn{3}{|c|}{ Rochns granificas n\$o alterndas } & \multicolumn{3}{|c|}{ Rochas granitices alieradus } \\
\hline Amostra & Facies: & Densidade & Amostre & $\begin{array}{l}\text { Tipo de } \\
\text { Allerapto }\end{array}$ & $\begin{array}{c}\text { Densidade } \\
\mathrm{J} / \mathrm{cm}^{3}\end{array}$ \\
\hline ABS-49 & ABS & 2,67 & AES-26 & (1) & 2,49 \\
\hline A.BS-50 & $\overline{A B S}$ & 2,67 & ABS 70 & (2) & 2,58 \\
\hline $\mathrm{ABS}-\mathbf{3 3}$ & ABS & 2,75 & ABS-326 & (3) & 2,66 \\
\hline ABS-91a & ABS & 2,66 & ABS-91b & (4) & 2,48 \\
\hline Medie & ABS & 2,69 & & & \\
\hline
\end{tabular}

ABS s anfibólio-biotita sienogranito

(1) rocha albitizada rica em cloríta; (2) rocha rica em carbonatos e argilo-mineria; (3) rocha silicificada e albitizada; (4) rocha avermelhada com argilizàção dos feldspatos

Tabela 3 - Composição químico-densimétrica $\left(\mathrm{g} / \mathrm{cm}^{3}\right)$ de rochas selecionadas do granito Serra dos Carajás, Pará Table 3 - Chemical-densimetric composition $\left(\mathrm{g} / \mathrm{cm}^{3}\right)$ of the Serra dos Carajás granite selected rocks

\begin{tabular}{|c|c|c|c|c|c|}
\hline & \multirow{2}{*}{$\begin{array}{c}\text { Granito nao } \\
\text { alcerado } \\
(\omega)\end{array}$} & \multicolumn{4}{|c|}{ Granito Alterado } \\
\hline & & ABS26 & ABS70 & ABS32b & ABS91b \\
\hline $\begin{array}{l}\mathrm{SiO}_{2} \\
\mathrm{Al}_{3} \mathrm{O}_{2} \\
\mathrm{Fe}_{2} \mathrm{O}_{3} \\
\mathrm{FeO} \\
\mathrm{MgO} \\
\mathrm{CoO} \\
\mathrm{Na}_{3} \mathrm{O} \\
\mathrm{K}_{2} \mathrm{O} \\
\mathrm{CO}_{2} \\
\mathrm{H}_{2} \mathrm{O} \\
\mathrm{Total}\end{array}$ & $\begin{array}{c}2,01 \\
0,33 \\
0,02 \\
0,04 \\
0,005 \\
0,03 \\
0,07 \\
0,14 \\
0,01 \\
0,02 \\
2,69\end{array}$ & $\begin{array}{l}1,88 \\
0,30 \\
0,06 \\
0,07 \\
0,01 \\
0,006 \\
0,08 \\
0,06 \\
0,02 \\
2,49\end{array}$ & $\begin{array}{l}1,85 \\
0,32 \\
0,04 \\
0,03 \\
0,001 \\
0,05 \\
0,06 \\
0,16 \\
0,03 \\
0,03 \\
2,58\end{array}$ & $\begin{array}{l}2,06 \\
0,30 \\
0,01 \\
0,04 \\
0,001 \\
0,04 \\
0,08 \\
0,07 \\
0,03 \\
0,02 \\
2,66\end{array}$ & $\begin{array}{l}1,89 \\
0,31 \\
0,01 \\
0,03 \\
0,007 \\
0,05 \\
0,16 \\
0,01 \\
0,01 \\
\mathbf{2 , 4 8}\end{array}$ \\
\hline
\end{tabular}

(†) midia das mosuras ABS43, ABS49, ABS50, ABS53 e ABS258

Potassa e soda têm comportamento inverso, se bem que a entrada de $\mathrm{K}_{2} \mathrm{O}$ tenha sido em maiores quantidades. Registram-se perdas de $\mathrm{Na}_{2} \mathrm{O}$ nos tipos 2 e $4\left(0,01\right.$ a $\left.0,02 \mathrm{~g} / \mathrm{cm}^{3}\right)$, e ganhos nos tipos 1 e $3\left(0,01 \mathrm{~g} / \mathrm{cm}^{3}\right)$, enquanto $\mathrm{K}_{2} \mathrm{O}$ é removido dos tipos 1 e $3\left(0,07\right.$ a $\left.0,08 \mathrm{~g} / \mathrm{cm}^{3}\right)$ e adicionado nos tipos 2 e $4\left(0,02 \mathrm{~g} / \mathrm{cm}^{3}\right)$. A constatação de ganho de potassa no tipo 4 , em que houve argilizàção dos feldspatos, pode indicar a presença de illita dentre os argilo-minerais. Prováveis erros analíticos podem justificar as proporções de água que, ao contrário do esperado, foi adicionada apenas na zona 2 , e até mesmo removida da zona 4. Já os aportes de $\mathrm{CO}_{2}$ são freqüentes (até $0,1 \mathrm{~g} / \mathrm{cm} 3$ ), notadamente nos tipos 2 e 3, o primeiro rico em microvênulas de calcita. Por fim, o $\mathrm{CaO}$ mostra perdas nos tipos 1 e 4 (pouco mais de $0,02 \mathrm{~g}$ / $\mathrm{cm}^{3}$ ) e ganhos nos outros dois, não ficando explicada a adição deste componente na rocha albitizada.

Este quadro deve refletir mudanças composicionais das soluções aquosas no tempo e no espaço, bem como equilibrios locais que levaram à estabilização de algumas fases às expensas de outras. São, assim, o resultado de diferentes reações fluido-rocha em diferentes domínios representados por distintos minerais ígneos primários (Ferry 1979).

VEIOS HIDROTERMAIS Grande parte do material removido das rochas graníticas ou a elas incorporado pela ação das soluções aquosas pr,ecipitou-se ao longo de planos de fraturas, gerando veios hidrotermais. Esses veios foram separados em quatro tipos (TI a T4) de acordo com o conteúdo mineralógico que apresentam ( Javier Rios \& Villas 1991).

Os veios TI, com espessura média de $5 \mathrm{~cm}$, consistem sobretudo de calcita e chegam a incorporar fragmentos da rocha granítica ou mesmo minerais primários ígneos. Os fluidos ricos em espécies de carbonato conseguiram, contudo, alterar apenas parcialmente os cristais de anfibólio e biotita com os quais a calcita está associada. Nas paredes desses veios podem ser observados agregados de turmalina substituindo fases máficas por pseudomorfose, assim como cristais de FK argilizados ou mesmo delgadas faixas de sericita e clorita, definindo um zoneamento irregular que, do centro do veio em direção às rochas encaixantes, mostra calcita $( \pm$ sulfetos $)=>$ sericita + clorita + quartzo $( \pm$ turmalina $)=>$ argilo-minerais Os sulfetos estão representados por calcopirita, cujos cristais apresentam núcleos com manchas de bornita e inclusões de pirita, bem como bordas alteradas para covelita.

Os veios T2, com espessura de até $50 \mathrm{~cm}$, são mais complexos e podem conter até oito fases. Ocasionalmente desenvolvem um zoneamento simétrico bem nítido, em que bandas de clorita e epidoto, às vezes antecedidas por quartzo leitoso, cedem lugar, em direção ao centro do veio, à associação quartzo + turmalina + albita + calcita + fluorita + sulfetos. A distribuição destas fases mais centrais é heterogênea, tanto que algumas delas não são observadas ao longo de certos intervalos. A sequência temporal é marcada pela aparição inicial de quartzo \pm turmalina, seguida da precipitação de albita, de calcita + fluorita e, finalmente, de sulfetos (calcopirita + pirita + molibdenita), os quais ocupam as zonas mais centrais do veio ou mesmo cortam zonas previamente formadas.

As vênulas de sulfetos, ou veios T3, são compostos dominantemente de calcopirita, além de pirita, molibdenita, bornita e covelita. A calcopirita, sem macias reconhecíveis, altera-se nas bordas para covelita e bornita. A pirita, que não mostra sinais de alteração, ocorre corno intercrescimentos de borda ou como inclusões na calcopirita. Já a molibdenita tem habitus lamelar, às vezes com bordas escamosas, e não é observada como inclusões nos outros sulfetos. A provável seqüência paragenética seria pirita $\Rightarrow$ calcopirita $=>$ molibdenita $=>$ bornita $=>$ covelita, havendo ampla superposição temporal entre os dois primeiros. Em certas microvênulas algumas fases dessa associação podem estar ausentes.

Um último tipo de veio estudado (T4), de natureza magmático-hidrotermal, consiste de duas associações minerais distintas. A mais precoce, que conformou a estrutura do veio, é de origem magmática e está representada por hornblenda hastingsítica e biotita. Estas fases máficas foram segregadas antes do granito completar sua solidificação e injetadas, como concentrados, ao longo de superfícies de descontinuidade que não chegam a caracterizar planos de fratura bem definidos, daí seu traçado irregular. A outra associação, mais tardia, é hidrotermal e composta de calcita + fluorita + clorita + escapolita(?) + pirita, esta última ocupando planos de clivagem do anfibólio e da biotita.

OS FLUIDOS AQUOSOS As características dos fluidos aquosos responsáveis pela alteração e mineralização do granito Serra dos Carajás foram recentemente estudadas (Javier Rios 1991; Javier Rios \& Villas 1991). O que se segue é uma síntese desses trabalhos, cujos resultados microtermométricos foram obtidos a partir do exame de inclusões fluidas presentes em cristais de quartzo, calcita e fluorita dos veios hidrotermais TI e T2.

Três tipos de inclusões fluidas aquosas foram identificadas: monofásicas líquidas, bifásicas e multifásicas. As inclusões bifásicas são aquosas e dominam em todos os minerais examinados. À temperatura ambiente, apresentam uma fase líquida e outra gasosa, que se homogeneiza na fase líquida $(\mathrm{L}+\mathrm{V} \rightarrow \mathrm{L})$. As inclusões multifásicas também são aquosas, podendo conter até três minerais de saturação, com os fluidos homogeneizando-se na fase líquida $(\mathrm{S}+\mathrm{L}+\mathrm{V} \rightarrow$ $\mathrm{S}+\mathrm{L} \rightarrow \mathrm{L})$. 
TIPOS DE ALTERACÃO

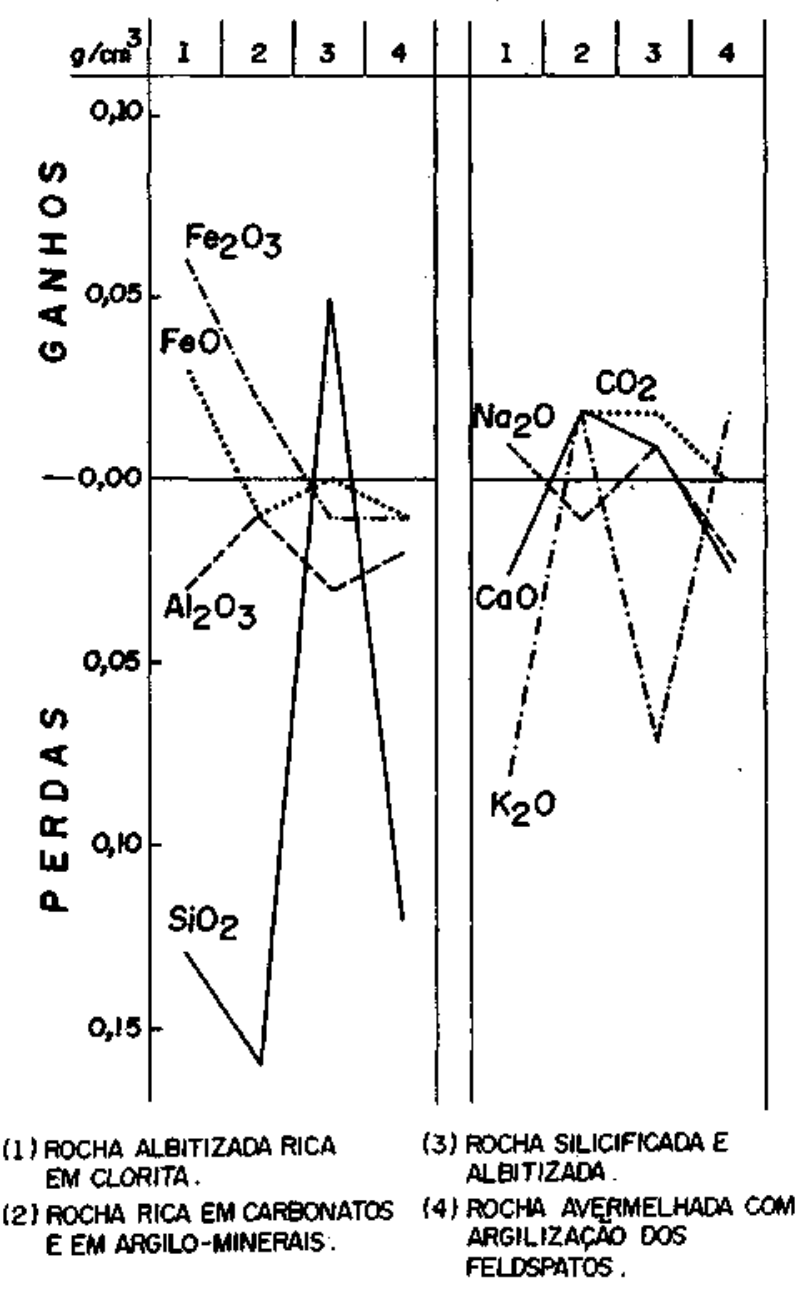

Figura 2 - Perdas e ganhos absolutos $\left(\mathrm{g} / \mathrm{cm}^{3}\right)$ de vários componentes em rochas com diferentes tipos de alteração durante os processos hidrotermais que atuaram sobre a fades ABS do granito Serra dos Carajás, Pará Figure 2 - Absolute losses and gains $\left(\mathrm{g} / \mathrm{cm}^{3}\right)$ of several components in differently hydrothermally altered rocks of the Serra dos Carajás ABS facies, Pará

As inclusões bifásicas primárias em cristais de calcita dos veios TI mostram formas variadas (pseudo-quadrangular, elongada, subarredondada e facetada), enquanto nos cristais de quartzo e fluorita dos veios T2 a mais comum é a subarredondada. Independentemente do mineral hospedeiro, essas inclusões têm dimensões inferiores a 25 jim e razões $\mathrm{VV}_{\mathrm{V}} / \mathrm{Vt}$ entre 0,08 e 0,15 .

Por seu turno, as inclusões multifásicas têm dimensões pouco maiores que as bifásicas e foram estudadas somente em cristais euédricos de quartzo. Bem pouco foram as observadas e estudadas em cristais de calcita, daí não terem sido consideradas representativas. O mineral de saturação mais comum é provavelmente a halita, havendo dois outros, de forma retangular à cúbica, ou mesmo de hábito irregular, cujos tamanhos excessivamente diminutos não permitiram sua identificação pelos métodos ópticos convencionais. $\mathrm{O}$ volume dos minerais de saturação pode atingir até 50\% da cavidade, enquanto a fase vapor ocupa cerca de $10 \%$ do volume da inclusão. Em geral, as inclusões multifásicas localizam-se nas zonas centrais dos cristais de quartzo, sendo pouco comum encontrá-las próximo às suas bordas. Aí observam-se principalmente as inclusões bifásicas, quer isoladas quer agrupadas ao longo de planos, que não ultrapassam, porém, os limites do cristal hospedeiro.

Os dados microtermométricos, obtidos a partir do exame de cerca de 300 inclusões (Tab.4), mostram que os fluidos que alteraram as rochas do Granito Serra dos Carajás podem ser aproximados pelo sistema $\mathrm{NaCl}-\mathrm{CaCl}_{2}-\left(\mathrm{MgCl}_{2}\right)-\mathrm{H}_{2} \mathrm{O}$ (Roedder 1984) com densidades variando entre 0,9 e $1,1 \mathrm{~g} /$ $\mathrm{cm}^{3}$ (Haas 1970).

As temperaturas de homogeneização total das inclusões bifásicas chegam a valores próximos de $200^{\circ} \mathrm{C}$, com intervalo variacional que não ultrapassa $60^{\circ} \mathrm{C}$, bem distintas, portanto, das inclusões multifásicas cujas temperaturas de homogeneização total ficam acima de $520^{\circ} \mathrm{C}$. Na verdade, nessas últimas inclusões não se verificou a dissolução completa dos minerais de saturação, mesmo no limite termal superior da platina Chaixmeca utilizada $\left(520^{\circ} \mathrm{C}\right)$, daí não ser possível medir as temperaturas de homogeneização total a nenhum grau de precisão.

Para a calcita dos veios T2, os dados são aproximados uma vez que as cavidades não são seguramente primárias. Quanto aos veios T1, as inclusões em cristais de calcita mostram uma relação nitidamente inversa entre salinidade e temperatura de homogeneização, com os fluidos mais salinos homogeneizando-se a temperaturas mais baixas (Fig.4). Comparando-se os fluidos responsáveis pela formação dos veios $\mathrm{T} 1$ e $\mathrm{T} 2$, na faixa termal de $160-190^{\circ} \mathrm{C}$, que é a mais freqüente, constata-se que eles têm diferentes valores de salinidade, os últimos podendo ser até sete vezes mais salinos que os primeiros, como indicam as temperaturas de fusão do gelo das inclusões (Fig.3). Além disso, a evolução desses fluidos foi distinta, pois, a temperaturas mais baixas $\left(130-160^{\circ} \mathrm{C}\right)$, os que precipitaram a calcita dos veios $\mathrm{T} 1$ tornaram-se gradativamente mais salinos que aqueles que precipitaram a fluorita dos veios T2. Apesar de os cristais de calcita serem facilmente cliváveis e, assim, suscetíveis a vazamento (Shepherd et al. 1985), o que recomenda cautela na interpretação dos dados microtermométricos, não foi constatada nenhuma alteração na fase gasosa ao se reexaminar as inclusões após a determinação de Th, concluindose não ter havido perda de fluido.

Ressalta-se que as inclusões multifásicas são similares às presentes em cristais de quartzo do granito não alterado, à pouca distância das porções hidrotermalizadas, podendo, assim, representar fluidos aquosos de origem magmática. Como esse tipo de inclusão tende a se concentrar nas partes mais centrais dos cristais, cedendo lugar, em direção às bordas, para as inclusões bifásicas de menor salinidade, deve ter havido diluição causada por mistura de fluidos externos ao granito, mais frios e de força iônica apenas moderada. Essa interpretação é corroborada pela grande diferença de temperatura de homogeneização entre as inclusões multifásicas $\left(>520^{\circ} \mathrm{C}\right)$ e as bifásicas $\left(<200^{\circ} \mathrm{C}\right)$. A evolução dos fluidos aquosos no sistema hidrotermal relacionado ao Granito Serra dos Carajás (Fig.4) sugere tanto a mistura dos fluidos, como também a provável precipitação de calcita nos veios TI diretamente das soluções externas ao granito. Essas soluções devem ter penetrado na intrusão aquecendo-se a temperaturas não muito acima de $200^{\circ} \mathrm{C}$. De início pouco salinas mas ácidas (pelo menos o suficiente para transportar íons carbonato), elas foram incorporando massa, particularmente $\mathrm{Ca}^{++} \mathrm{e} \mathrm{Na}^{+}$, à medida em que destruíam fases primárias do granito e, dessa forma, tornaram-se paulatinamente mais salinas; ao mesmo tempo, foram perdendo energia termal com o conseqüente abaixamento da temperatura. $\mathrm{Na}$ verdade, a evolução dos fluido ${ }^{\mathrm{r}} \mathrm{s}$ que precipitaram calcita nos veios $\mathrm{T} 1$ deve ter sido bem mais complexa, com períodos de flutuação do $\mathrm{pH}$ que pode ter levado à precipitação e dissolução de cristais de carbonates já formados, explicando, assim, a presença aleatória de inclusões de distintas salinidades lado a lado em um mesmo cristal hospedeiro. 
Cabe notar, ainda, que apesar de as soluções externas ao granito terem sido ricas em íons carbonato, não foram detectados inclusões em que o $\mathrm{CO}_{2}$ estivesse presente na fase vapor.

A composição das soluções aquosas que alteraram as rochas do granito Serra dos Carajás, representada pelo sistema $\mathrm{NaCl}-\mathrm{CaCl}_{2}-\left(\mathrm{MgCl}_{2}\right)-\mathrm{H}_{2} \mathrm{O}$, é compatível não só com o conteúdo mineral dos veios, como também com os dados do balanço de massa da interação fluido-rocha, em especial para aquelas em que a argilização foi mais intensa. Ca e $\mathrm{Na}$ foram transferidos do granito para as soluções, porém foram seletivamente reincorporados a outros domínios à medida em que calcita ou albita iam sendo precipitadas. Daí o registro de perda ou ganho destes elementos conforme o tipo de alteração. Claro que aquele sistema é uma simplificação e não corresponde à real composição dos fluidos. Outros componentes estiveram presentes e controlaram a formação dos demais minerais de alteração. De qualquer maneira, o balanço de massa permitiu mapear, através desses minerais, a variação composicional dos fluidos registrada em diferentes pontos do corpo granítico.

CONDIÇÕES DE FORMAÇÃO DOS VEIOS E DA MINERALIZAÇÃO DE SULFETOS O ambiente de formação dos veios hidrotermais e da deposição dos sulfetos foi analisado através de diagramas de fugacidade e atividade, correspondendo a subsistemas químicos que parcialmente representam o sistema aquoso de multicomponentes do granito Serra dos Carajás. A seleção dos subsistemas teve por base as fases mineralógicas que foram identificadas, enquanto as condições termais apoiaram-se nos dados microtermométricos.

A temperatura de $200^{\circ} \mathrm{C}$ foi escolhida como representativa da mistura das soluções magmáticas (Fig.4), a qual é bem próxima ao maior valor $\left(190,5^{\circ} \mathrm{C}\right)$ encontrado para as temperaturas de homogeneização das inclusões bifásicas dos veios T2, consideradas como temperaturas mínimas de aprisionamento de fluidos. Para a deposição de sulfetos, temperaturas mais baixas, em torno de $150^{\circ} \mathrm{C}$, seriam, por certo, mais apropriadas, uma vez que essa associação foi a última a se precipitar, conforme indicaram informações de campo e petrográfícas. Contudo, as relações espaciais entre as fases não se alterariam, a não ser por mudanças pouco expressivas nos limites de seus campos de estabilidade. Não invalidariam, assim, as conclusões a que se chegaram à temperatura de $200^{\circ} \mathrm{C}$.
A ausência de pirrotita na assembléia de sulfetos e a ocorrência apenas local de hematita permitiram, através do subsistema $\mathrm{FeO}-\mathrm{H}_{2} \mathrm{~S}-\mathrm{H}_{2} \mathrm{O}-\mathrm{O}_{2}$, fixar, a $200^{\circ} \mathrm{C}$, fugacidades mínimas de $\mathrm{O}_{2}$ em cerca de $10^{-45}$ atm. Da mesma forma, a escassez de óxidos de ferro, tanto magnetita como hematita, indica fugacidades mínimas de $\mathrm{H}_{2} \mathrm{~S}$ da ordem de $\mathrm{IO}^{\prime 5}$ atm (Fig.5). Sob essas condições poderia ter havido também precipitação de cassiterita $\left(\mathrm{SnO}_{2}\right)$ ou berndtita $\left(\mathrm{SnS}_{2}\right)$, o que não ocorreu por exclusiva falta de $\mathrm{Sn}$ nas soluções aquosas, confirmando, assim, o caráter não especializado em estanho das fácies estudadas no granito Serra dos Carajás (Javier Rios et al. 1992).

Com base no subsistema $\mathrm{Na}_{2} \mathrm{O}-\mathrm{K}_{2} \mathrm{O}-\mathrm{Al}_{2} \mathrm{O}_{3}-\mathrm{SiO}_{2}-\mathrm{HCl}-$ $\mathrm{H}_{2} \mathrm{O}$, com quartzo em excesso, pode-se sugerir uma trajetória de variação composicional das soluções hidrotermais



Figura 3 - Histograma de frequência das temperaturas de fusão do gelo $\left(T_{f(g)}\right)$ de inclusões fluidas bifásicas estudadas em cristais de quartzo, calcita e fluo ri tá dos veios T1 e 72 . Os valores de $T_{f(g)}$ da calcita dos veios $T 2$ são aproximados. Os intervalos das temperaturas de homogeneização $\left(T_{h}\right)$ estão assinalados no alto das colunas

Figure 3 - Frequency histogram of melting ice temperatures $\left(\mathrm{T}_{\mathrm{f}(\mathrm{g})}\right)$ from two-phase inclusions in quartz, calcite and fluorite crystals from $\mathrm{Tl}$ and $\mathrm{T} 2$ veins. Values of $\mathrm{T}_{\mathrm{f}(\mathrm{g})}$ for $\mathrm{T} 2$ vein calcite are approximated. Homogenization temperature $\left(\mathrm{T}_{\mathrm{b}}\right)$ ranges are indicated on the top of the columns.

Tabela 4 - Quadro sumarizando as principais características físico-químicas dos fluidos responsáveis pela formação dos veios $T 1$ eT2. $T_{h}=$ temperatura de homogeneização total; $T_{M}=$ temperatura de fusão do gelo; \% - salinidade em equivalente em peso (\%) de $\mathrm{NaCl}$

Table 4 - Summary of the main physico-chemical characteristics of the aqueous fluids that caused the formation of $\mathrm{T} 1$ and $\mathrm{T} 2 \mathrm{veins}$. $\mathrm{T}_{\mathrm{h}}=$ total homogenization temperature; $\mathrm{T}_{\mathrm{f}(\mathrm{g})}=$ ice meilting temperature; $\%=$ salinity in weight $\%$ equivalent $\mathrm{NaCl}$

\begin{tabular}{|c|c|c|c|c|}
\hline \multicolumn{5}{|c|}{$\begin{array}{l}\text { VEJOS Tl } \\
\text { Sistema: } \mathrm{NaCl}-\mathrm{CaCl}_{2}-\left(\mathrm{MgCl}_{2}\right)-\mathrm{H}_{2} \mathrm{O} ; \text { Densidades: } 0,9 \text { a } 1,0 \mathrm{~g} / \mathrm{cm}^{3} ; \text { paragenese: calcita } \Rightarrow \text { sulfetos }\end{array}$} \\
\hline Calcita & $\begin{array}{l}\text { IFBP subarredondadas } \\
\text { IFBP pseudo-retangulares } \\
\text { IFBP elongadas (bastão) }\end{array}$ & $\begin{array}{c}\text { Tht } \\
140 \text { a } 150^{\circ} \mathrm{C} \\
160 \text { a } 190^{\circ} \mathrm{C} \\
160 \text { a } 190^{\circ} \mathrm{C}\end{array}$ & $\begin{array}{c}\mathrm{Tf}(\mathrm{g}) \\
+28 \mathrm{a}-19,8^{\circ} \mathrm{C} \\
112^{\circ} \mathrm{C} \\
-3,4 \mathrm{a}-2,2^{\circ} \mathrm{C}\end{array}$ & $\begin{array}{c}x \\
23 \text { a } 26 \% \\
16 \% \\
3,5 \text { a } 5 \%\end{array}$ \\
\hline \multicolumn{5}{|c|}{$\begin{array}{l}\text { VEIOS T2 } \\
\text { Sistema: } \mathrm{NaCl}-\mathrm{CaCl}_{2}-\left(\mathrm{MgCl}_{2}\right)-\mathrm{H}_{2} \mathrm{O} ; \text { Densidades: } 1,0 \text { a } 1,1 \mathrm{~g} / \mathrm{cm}^{3} ; \text { paragênese:quartzo } \Rightarrow \text { calcita } \Rightarrow \text { sulfetos }\end{array}$} \\
\hline $\begin{array}{l}\text { Quartzo } \\
\text { Calcita } \\
\text { Fluotita }\end{array}$ & $\begin{array}{c}\text { IFPM } \\
\text { IFBP } \\
\text { IFBS }(?) \\
\text { IFBP }\end{array}$ & $\begin{array}{c}\text { Tht } \\
>520^{\circ} \mathrm{C} \\
166 \text { a } 190^{\circ} \mathrm{C} \\
160 \text { a } 190^{\circ} \mathrm{C} \\
130 \text { a } 167^{\circ} \mathrm{C}\end{array}$ & $\begin{array}{c}\text { Tf(g) } \\
-23,9 \text { a }-25,3^{\circ} \mathrm{C} \\
\text { nd } \\
-7,8 \text { a }-9,5^{\circ} \mathrm{C}\end{array}$ & $\begin{array}{c}x \\
>28 \% \\
24,5 \% \\
<5 \% \\
9,5 \text { a } 12 \%\end{array}$ \\
\hline
\end{tabular}




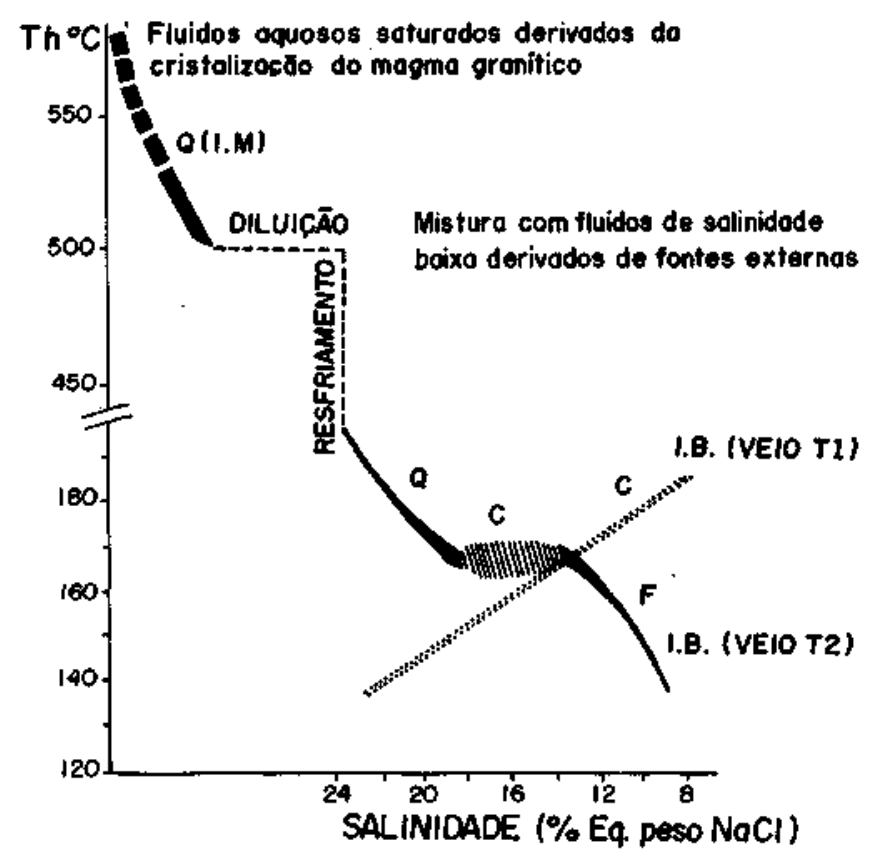

Figura 4 - Diagrama de temperatura de homogeneização (Th) versus salinidade, indicando a evolução dos fluidos aquosos no sistema hidrotermal relacionado ao granito Serra dos Carajás. Notar a relação inversa entre $T_{h} e$ salinidade nas inclusões bifásicas em cristais de calcita dos veios T2. $Q$ - quartzo; $C$ - calcita; $F=$ fluorita; $I M=$ inclusões multifâsicas; IB = inclusões bifásicas Figure 4- Homogenization temperature $\left(\mathrm{T}_{\mathrm{h}}\right)$-salinity diagram showing the evolution of the aqueous fluids related to the Serra dos Carajás granite hydrothermal system. Observe the inverse relation between Th and salinities of the two-phase inclusions in T2 vein calcite crystals. Q= quartz; $\mathrm{C}=$ calcite; $\mathrm{F}$ = fluorite; $\mathrm{IM}=$ multiphase inclusions; IB = twophase inclusions

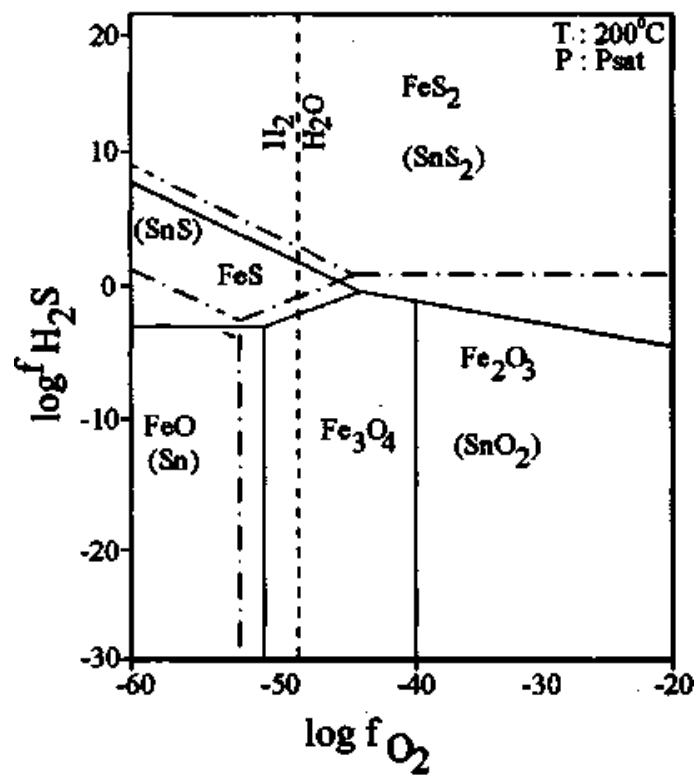

Figura 5 - Superposição das relações de fases nos sistemas $\mathrm{SnO}_{2}-\mathrm{H}_{2} \mathrm{~S}-\mathrm{H}_{2} \mathrm{O}-\mathrm{O}_{2}$ e $\mathrm{FeO}-\mathrm{H}_{2} \mathrm{~S}-\mathrm{H}_{2} \mathrm{O}-\mathrm{O}_{2}$ em função das fugacidades de $\mathrm{O}_{2}$ e $\mathrm{H}$ para $\mathrm{a}_{\mathrm{H} 2 \mathrm{O}}$ - L As linhas interrompidas (traço e ponto) representam os limites dos campos de estabilidade da fases de Sn. Baseado em Jackson \& Helgeson (1985) Figure 5 - Overlaped phase relations in the systems $\mathrm{SnO}_{2}-\mathrm{H}_{2} \mathrm{~S}-\mathrm{H}_{2} \mathrm{O}-\mathrm{O}_{2}$ and $\mathrm{FeO}-\mathrm{H}_{2} \mathrm{~S}-\mathrm{H}_{2} \mathrm{O}-\mathrm{O}_{2}$ as function of $\mathrm{O}_{2}$ and $\mathrm{H}_{2} \mathrm{~S}$ fugacities for $\mathrm{a}_{\mathrm{H} 20}=1$. The broken lines (dash and dot) represent the stability field boudaries of the $\mathrm{Sn}$ phases. After Jackson \& Helgeson (1985) desde o campo da caolinita até a saturação em albita, passando pelo campo da sericita (Fig.6). Os valores de log $\left(\mathrm{a}_{\mathrm{K}+} / \mathrm{a}_{\mathrm{H}+}\right)$, a $200^{\circ} \mathrm{C}$, devem ter ficado abaixo de 4,1 , pois não foi observado feldspato potássico nos veios ou nas rochas alteradas como mineral secundário. Valendo-se do subsistema $\mathrm{CaO}-\mathrm{Al}_{2} \mathrm{O}_{3}-\mathrm{SiO}_{2}-\mathrm{HF}-\mathrm{H}_{2} \mathrm{O}$, também saturado em quartzo (Fig.7), pôde-se estimar valores de $\log \left(\mathrm{ac}_{\mathrm{a}++} / \mathrm{a}_{\mathrm{H}+}^{2}\right)$ e $\log$ $\left(\mathrm{a}_{\mathrm{H}+} \cdot \mathrm{a}_{\mathrm{F}}.\right)$ respectivamente em cerca de $8,9 \mathrm{e}-9,6$, a $200^{\circ} \mathrm{C}$, definidos pela superfície de saturação da fluorita e pelas ausências de topázio e laumontita no sistema hidrotermal do granito Serra dos Carajás.

Já a presença de calcita nos veios hidrotermais e eventualmente nas rochas alteradas implicaria, para aquele valor de $\log \left(\mathrm{a}_{\mathrm{Ca}++} / \mathrm{a}^{2} \mathrm{H}_{+}\right)$, fugacidades de $\mathrm{CO}_{2}$ pouco acima de 1 atm a uma temperatura de $200^{\circ} \mathrm{C}$, conforme mostram os cálculos abaixo (para $\mathrm{a}_{\mathrm{H} 2 \mathrm{O}}=1$ )

$$
\begin{aligned}
& \mathrm{CaCO}_{3}+2 \mathrm{H}^{+} \Leftrightarrow \mathrm{Ca}^{++}+\mathrm{H}_{2} \mathrm{O}+\mathrm{CO}_{2(2)}
\end{aligned}
$$

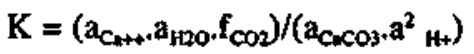

Como $\log \mathrm{K}\left(200^{\circ} \mathrm{c}\right)=8,95$ (Helgeson 1969) e a calcita é

considerada fase pura, entao

$$
\begin{aligned}
& 8,95=\log \left(\mathrm{a}_{\mathrm{CO}++} / \mathrm{a}^{2} \mathrm{H+}\right)+\log \mathrm{f}_{\mathrm{CO}} \\
& \log \mathrm{f}_{\mathrm{CO} 2}=0,05 \\
& f_{\mathrm{CO} 2}=1,12 \mathrm{~atm}
\end{aligned}
$$

Como as temperaturas de homogeneização das inclusões bifásicas em cristais de fluorita variaram entre 130 e $167^{\circ} \mathrm{C}$, mais representativo seria descrever o subsistema $\mathrm{CaO}$ $\mathrm{Al}_{2} \mathrm{O}_{3}-\mathrm{SiO}_{2}-\mathrm{HF}-\mathrm{H}_{2} \mathrm{O}$ a $150^{\circ} \mathrm{C}$ (média ponderada das medidas feitas). Nesse caso, os limites máximo e mínimo para $\log \left(a_{\mathrm{H}^{+}} \bullet \mathrm{a}_{\mathrm{F}-}\right)$ seriam respectivamente $-9,9$ e $-9,2$, enquanto para $\log \left(\mathrm{a}_{\mathrm{Ca}+} / \mathrm{a}_{\mathrm{H}+}^{2}\right)$ seriam 8,75 e 9,75 respectivamente. A fugacidade de $\mathrm{CO}_{2}$.então, teria variado entre cerca de 2,0 e 0,2 atm a $150^{\circ} \mathrm{C}$, mantidas as mesmas restrições quanto às ausências de topázio e laumontita.

Todos esses valores são obviamente aproximados e servem apenas para estabelecer alguns limites no ambiente químico em que se deu a alteração hidrotermal do granito Serra dos Carajás. Em particular, a atividade da água não deveria ter sido considerada igual à unidade, como foi feito, pois os fluidos estudados, com salinidades entre 9,5 e 25,5 equiv. em peso de $\mathrm{NaCl}$, correspondendo, portanto, a soluÇões de 1,5 a 4,0 molal ( $\mathrm{NaCl})$, a desviam significativamente daquele valor.

CONCLUSÕES A alteração hidrotermal do granito Serra dos Carajás, no setor norte, apesar de generalizada, foi fraca, não conseguindo modificar mais de $10 \%$ da associação mineralógica primária. Da mesma forma, embora a ocorrência de sulfetos seja comum, eles não chegam a representar $1 \%$ do volume do granito hospedeiro, resultando em teores inexpressivos de $\mathrm{Cu}$ e Mo. Os principais tipos de alteração são a cloritização das fases máficas, sericitização ou argilização dos feldspatos, albitização do feldspato potássico e epidotização da biotita, além de sulfidização, carbonatação e, em menor escala, silicificação das rochas. Do ponto de vista químico, houve, globalmente, perdas de massa do granito para as soluções aquosas, as quais variaram de 0,03 a $0,21 \mathrm{~g} / \mathrm{cm}^{3}$, dependendo do tipo de alteração considerado, o menor valor referindo-se às rochas silicificadas e albitizadas, e o maior àquelas com argilização dos feldspatos. Para uma densidade média de $2,69 \mathrm{~g} / \mathrm{cm}^{3}$ para o granito não alterado, este maior valor representa somente cerca de $8 \%$ da massa transferida. Componente a componente, as maiores perdas foram registradas com a silica $\left(0,12\right.$ a $\left.0,16 \mathrm{~g} / \mathrm{cm}^{3}\right)$, alumina $\left(0,01\right.$ a $\left.0,03 \mathrm{~g} / \mathrm{cm}^{3}\right) \mathrm{e}$ potassa $\left(0,07\right.$ a $\left.0,08 \mathrm{~g} / \mathrm{cm}^{3}\right)$, enquanto os maiores ganhos 


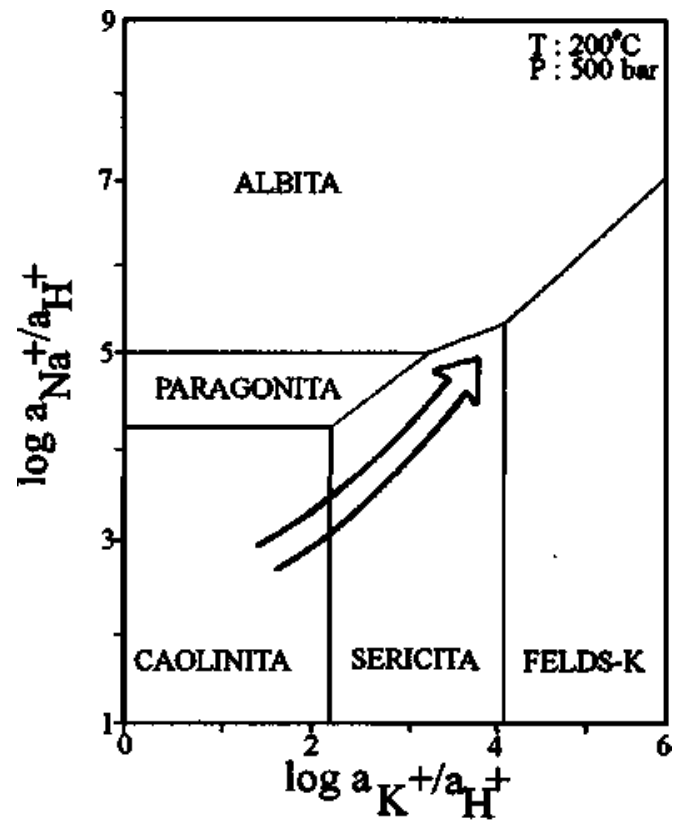

Figura 6 - Relações de fases no sistema $\mathrm{K}_{2} \mathrm{O}-\mathrm{Na}_{2} \mathrm{O}-\mathrm{Al}_{2} \mathrm{O}_{3}$ $\mathrm{SiO}_{2}-\mathrm{HCl}-\mathrm{H}_{2} \mathrm{O}$ saturado com quartzo (Jackson \& Helgeson 1985), mostrando a provável evolução das soluções aquosas no sistema hidrotermal relacionado ao granito Serra dos Carajás

Figure 6 - Phase relations in the system $\mathrm{K}_{2} \mathrm{O}-\mathrm{Na}_{2} \mathrm{O}-\mathrm{Al}_{2} \mathrm{O} 3-\mathrm{SiO} 2-\mathrm{HCl}-\mathrm{H}_{2} \mathrm{O}$ with quartz saturation (Jackson \& Helgeson 1985), showing a possible evolution of the aqueous solutions in the Serra dos Carajás granite hydrothermal system

pertencem ao ferro, quer $\mathrm{Fe}_{2} \mathrm{O}_{3}\left(0,06 \mathrm{~g} / \mathrm{cm}^{3}\right)$ quer $\mathrm{FeO}(0,03$ $\left.\mathrm{g} / \mathrm{cm}^{3}\right)$, e $\mathrm{CO}_{2}\left(0,02 \mathrm{~g} / \mathrm{cm}^{3}\right)$. Para os demais, houve tanto perda como ganho de massa de acordo com o tipo de alteração presente na rocha amostrada.

Os principais produtos da alteração hidrotermal são os veios decorrentes do preenchimento de fraturas de várias direções, em particular os de estrutura complexa compostos de quartzo + albita + clorita + epidoto + turmalina + calcita + fluorita + sulfetos (veios T2). Durante a circulação convectiva, soluções aquosas magmáticas e não magmáticas se misturaram, registrando concentrações equivalentes a 1,5$4,0 \mathrm{~m}(\mathrm{NaCl})$. No intervalo termal de 200 a $300^{\circ} \mathrm{C}$ estes minerais precipitaram-se de acordo com a seqüência paragenética de silicates para carbonatos e fluoretos e, finalmente, para sulfetos.

A $200^{\circ} \mathrm{C}$ foram estimadas fugacidades mínimas de $\mathrm{O}_{2}$ da ordem de $10^{-45}$ atm e máximas não muito acima de $\mathrm{IO}^{, 40} \mathrm{~atm}$, bem como fugacidades mínimas de $\mathrm{H}_{2} \mathrm{~S}$ em torno de $\mathrm{IO}^{\prime \prime}$ atm, haja vista a escassez de hematita ou magnetita e a ausência de pirrotita. A essa mesma temperatura, calculouse em 1,12 atm a fugacidade de $\mathrm{CO}_{2}$ para um valor de $\mathrm{ac}_{\mathrm{a}++} /$ $\mathrm{a}_{\mathrm{H}^{+}}^{2}=10^{8,9}$ que foi fixado pela superfície de saturação da fluorita fora dos campos de estabilidade da laumontita e a do topázio - ambos ausentes no sistema estudado -, porém dentro do campo da caolinita - fase comum nas rochas alteradas.

Os dados microtermométricos combinados com informações de campo, petrográfícas e geoquímicas (Parte I deste trabalho) permitiram montar um quadro evolutivo (Fig.8) para o granito Serra dos Carajás, que abrange os estágios magmático, tardimagmático-pneumatolítico e hidrotermal. Em particular, o estágio hidrotermal está representado por fluidos aquosos derivados tanto do magma granítico como das rochas encaixantes, cuja mistura deve tê-los resfriado a

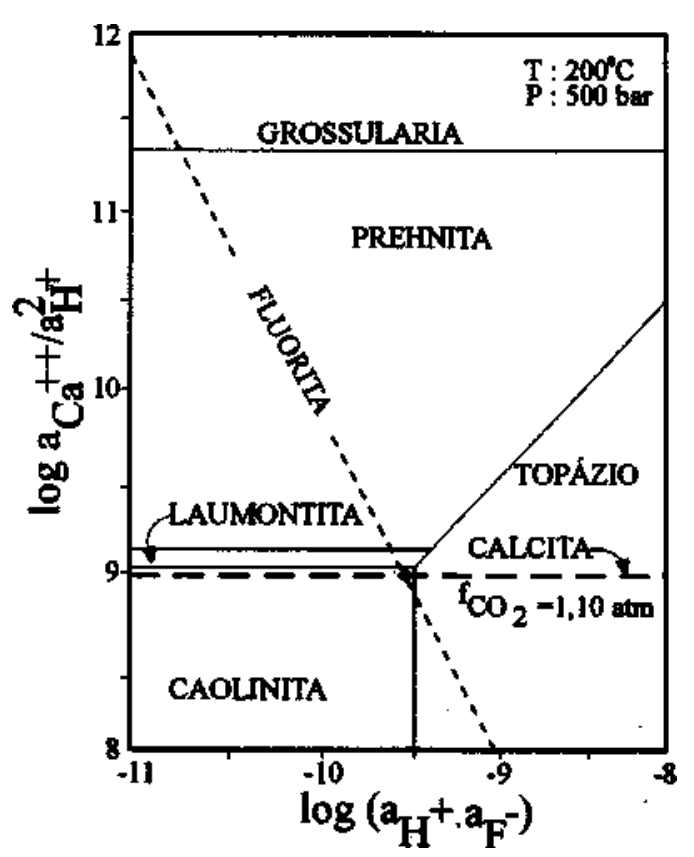

Figura 7 - Relações de fases no sistema $\mathrm{CaO}-\mathrm{Al}_{2} \mathrm{O}_{3}-\mathrm{SiO}_{2}-$ $\mathrm{HF}-\mathrm{H}_{2} \mathrm{O}$ saturado com quartzo e com $a_{\mathrm{H} 2 \mathrm{O}}=L$ As Unhas tracejadas marcam as superficies de saturação da fluorita e da calcita, a última para $f_{\mathrm{CO2}}-1,12 \mathrm{~atm}$. Vide explicação no texto. Modificado de Jackson \& Helgeson (1985) Figure 7 - Phase relations in the system $\mathrm{CaO}-\mathrm{Al}_{2} \mathrm{O}_{3}-\mathrm{SiO}_{2}-\mathrm{HF}-\mathrm{H}_{2} \mathrm{O}$ with quartz saturation and $\mathrm{a}_{\mathrm{H} 20}=1$. The broken lines represent saturation surfaces of fluorite and calcite, the latter for $\mathrm{f}_{\mathrm{CO} 2}=1,12 \mathrm{~atm}$. See text for explanation. Modified from Jackson \& Helgeson (1985).



Figura 8 - Quadro evolutivo esqiiemático do graniio Serrei dos Carajás, destacando os estágios magmático, magmático-pneumtolítico e hidrotermal, este último representado por soluções oriundas do magma granítico e de fontes externas

Figure 8 - Evolutive scheme of the Serra dos Carajás granite which includes the magmatic, magmatic-pneumatolitic and hydrothermal stages, the latter represented by solutions derived from both the granitic magma and host rocks

temperaturas da ordem de $200^{\circ} \mathrm{C}$. As soluções não magmáticas, ricas em espécies de carbonato e de sulfetos, devem ter percolado unidades carbonatadas de protominério de manganês da área contígua do Igarapé Azul, bem como seqüências vulcanossedimentares circunvizinhas que hos- 
pedam importantes depósitos de sulfetos de cobre da região de Carajás. Explica-se, dessa forma, a presença de abundante calcita nos veios, às vezes associada à piedmontita, como também a predominância de calcopirita na assembléia de sulfetos.

Agradecimentos Apoio financeiro parcial para realização desta pesquisa veio do CNPq (proc. 40.0189/90-97 FV), cabendo a Rio Doce Mineração (DOCEGEO) o apoio logístico sem o qual os trabalhos de campo não teriam sido desenvolvidos. A ambas instituições nosso mais profundo reconhecimento. Agradecimentos também são devidos ao CDTN-CNEN, onde foram realizados os estudos de inclusões fluidas, e ao CG-UFPA, onde o programa de mestrado do primeiro autor foi desenvolvido. Este trabalho se beneficiou bastante das críticas e sugestões feitas pelos Drs. Basile Kotschoubey e Roberto Dall'Agnol, ambos do CG-UFPA, bem como pelos Drs. Roberto Perez Xavier (UNICAMP) e Ian McReath (USP) que foram indicados como revisores desta Revista.

\section{REFERÊNCIAS BIBLIOGRÁFICAS}

ALMEIDA, R.C.C. 1980. Contribuição à petrologia do Cranito Central da Serra dos Carajás, Belém. 64p. (Dissertação de Mestrado, NGCC/ UFPA).

DALL'AGNOL, R. 1982. Estudo comparativo de alguns maciços graníticos pós-Transamazônicos da Amazônia Oriental. In: CONGR. BRÁS. GEOL., 32. Salvador, 1982. Anais... Salvador, SBG. v. 2, p. 500-513.

DALL'AGNOL, R.; SCHUCKMANN, W.K; BASEI. M.A.S. \& SCHELLER, T. 1984. Novos dados geocronológicos e estudo de elementos traços de maciços granfticos anorogênicos da Amazônia Oriental, Estado do Pará (Brasil). In: SIMP. GEOL. AMAZ., 2. Manaus, 1984. Anais... Manaus, SBG. p. 59-74.

DALL'AGNOL, R.; LAFON, J.M. \& MACAMBIRA, M.B. 1994. Proterozoic anorogenic magmatism in the Central Amazonian Craton. Mineral. Petrol, 50(1/3):! 13-138.

FERRY, J.M. 1979. Reactions mechanisms, physical conditions, and mass transfer during hydrotermal alteration of mica and feldspar in granitic rocks from south-central Maine, USA. Cont. Mineral. Petrol., 68:125-139.

GASTAL, M.C. 1988. Magmatismo ácido-intermediário do Proterozoico Médio na região de Rio Maria, sul do Pará: discussão quanto à tipologia. In: CONG. BRAS. GEOL., 35, Belém, 1988. Anais... Belém, SBG-Núcleo Norte, v.3, p. 1132-1146.

GONÇALVEZ, M.G.B.; DALL'AGNOL, R.; VIEIRA, E.A.P.; MACAMBIRA, M.J. \& DELLA SENTA, N. 1988. Geologia do maciço anorogênico Cigano, vale do rio Parauapebas (PA). In: CONGR. BRÁS, GEOL., 35, Belém, 1988. Anais... Belém, SBG-Nácleo Norte, v. 3, p. 1132-1146.

HAAS, J.L. 1970. An equation for the density of vapor saturated NaCl$\mathrm{H}_{2} \mathrm{O}$ solutions from 75 to $325^{\circ}$ C. Amer. Jour. Sci., 269:489-493.

HELGESON, H.C. 1969. Thermodynamics of hydrothermal systems at elevated temperatures and pressures. Amer. Jour. Sci., 267:729-804.
JACKSON, K.J. \& HELGESON, H.C. 1985. Chemical and thermodynamic constraints on the hydrothermal transport and deposition of tin: II. Interpretation of phase relations in the Southeast Asian Tin Belt. Econ. Ceol, 80(5): 1365-1379.

JAVIER RIOS, F. 1991. O granito Central da Serra dos Carajás: fades petrográjlcas e alteração hidrotermal do setor norte. Belém, 152p. (Dissertação de Mestrado, CG-UFPA).

JAVIER RIOS, F. \& VILLAS, R.N.N. 1991. Veios hidrotermais com mineralização de sulfetos, Granito Central, Serra dos Carajás. In: SIMP. GEOL. AMAZ., 3. Belém, 1991. Anais...Belém, SBG, Núcleo Norte, p. 336-349.

JAVIER RIOS, F.; VILLAS, R.N.N. \& DALL'AGNOL, R. 1992.0 granito Central da Serra dos Carajás. I: Fácies petrográficas e evolução petrológica do setor norte. In: CONG. BRAS. GEOL., 37. São Paulo, 1992. Boletim de Resumos Expandidos. São Paulo, SBG. v. 1, p. 384-385.

ROEDDER, E. 1984. Fluid inclusions. Reviews in Mineralogy. Min. Soe. Amer., v. 12,664p.

SHEPERD, T.J.; RANKIN, A.H. \& ALDERTON, D.H.M. 1985. A practical guide to fluid inclusion studies. Blackie \& Son Ltd., Glasgow, 239p.

TEIXEIRA, N.P \& ANDRADE, W.L.G. 1992, Caracterização petrográfica dos "stocks" graníticos Benedita e Ubim Sul, região de São Félix do Xingu, Pará. Série Ciências da Terra. Boi. Museu Paraense Emílio Goeldi, 4:3-33.
MANUSCRITO A828

Recebido em 06 de fevereiro de 1995 Revisão do autor em 20 de marco de 1996 Revisão aceita em 22 de março de 1996 